\title{
Sleep Quality, Mood, Alertness and Their Variability in CKD and ESRD
}

\author{
Maria-Eleni Roumelioti ${ }^{a}$ Christos Argyropoulos ${ }^{a}$ Daniel J. Buysse ${ }^{b}$ \\ Harry Nayar $^{d}$ Steven D. Weisbord ${ }^{\mathrm{a}, \mathrm{c}}$ Mark L. Unruh ${ }^{\mathrm{a}}$ \\ ${ }^{a}$ Renal-Electrolyte Division, University of Pittsburgh Medical Center, ${ }^{b}$ Department of Psychiatry, University of \\ Pittsburgh School of Medicine, ' Renal Section and Center for Health Equity Research and Promotion, \\ VA Pittsburgh Healthcare System and ${ }^{\mathrm{d}}$ Drexel University School of Medicine, Pittsburgh, Pa., USA
}

\section{Key Words}

Mood $\cdot$ Sleep quality $\cdot$ Alertness $\cdot$ Chronic kidney disease $\cdot$

End-stage renal disease $\cdot$ Pittsburgh Sleep Diary $\cdot$ SF-36 than either the advanced CKD patients or the controls. Conclusion: Advanced CKD and dialysis dependency are associated with impaired and highly variable sleep quality, mood, and alertness.

Copyright $\odot 2010$ S. Karger AG, Basel

\begin{abstract}
Background/Aims: Little is known about the association of chronic kidney disease (CKD) with sleep quality, mood, and alertness. In this report, we assessed these symptoms among patients with advanced CKD (stages 4-5) and those with end-stage renal disease (ESRD) and compared them to healthy controls without known kidney disease. Methods: Patients were recruited from local dialysis units, outpatient nephrology clinics and the Thomas E. Starzl Transplant Institute. Healthy control subjects matched for age, gender and race were drawn from an archival database. Daily symptoms of sleep quality, mood, and alertness were assessed by visual analogue scales of the Pittsburgh Sleep Diary. Healthrelated quality of life was assessed by the Short Form-36 instrument. Results: Sixty-nine dialysis patients and 23 patients with advanced CKD demonstrated worse scores in sleep quality, mood, and alertness ( $p<0.001)$ than controls. In adjusted analyses, European-American race, dialysis dependency, younger age, and physical performance SF-36 components were significantly associated with poor sleep quality, mood and alertness ( $p<0.05$ ). The dialysis population demonstrated higher day-to-day variability in scores
\end{abstract}

\section{Introduction}

Poor health-related quality of life (HRQOL) in patients with advanced chronic kidney disease (CKD) remains a challenge to both patients and physicians [1]. In particular, daytime sleepiness, fatigue and mood disturbances are common and important symptoms associated with poor HRQOL among the CKD [2,3] and the endstage renal disease (ESRD) populations [4,5]. Even though similar symptoms are commonly reported by patients with CKD [6-8], the severity and the day-to-day variability of such symptoms in the different stages of renal disease relative to normal controls is largely unknown. To our knowledge, the potential for these symptoms to exhibit a substantial degree of day-to-day variation in patients on or near dialysis dependency has not been previously appreciated in the literature. Yet, a high degree of variability in mood, sleep quality and alertness could hinder the recognition and delay the treatment of these symptoms by providers [6].

\section{KARGER}

(C) 2010 S. Karger AG, Basel

Fax +41613061234 E-Mail karger@karger.ch www.karger.com www.karger.com/nec
Mark L. Unruh, MD, MSc

University of Pittsburgh Medical Center

Renal-Electrolyte Division, 200 Lothrop Street, PUH C-1111

Pittsburgh, PA 15213 (USA)

Tel. +1 412647 2571, Fax +1 412647 4787, E-Mail unruh@ pitt.edu 
To address these gaps in knowledge, we examined daily sleep quality, mood and alertness in patients with stages 4-5 CKD or ESRD dependent on dialysis and in a comparison group of adults matched for age, gender and race. In order to characterize the variability in the severity of these symptoms, we prospectively recorded such data in diaries completed by study participants over a period of 7 to 14 days. In carrying out this investigation, we hypothesized that patients on dialysis [hemodialysis, (HD) or peritoneal dialysis (PD)] would demonstrate both worse (lower) and more variable sleep quality, mood and alertness compared to patients with stages $4-5$ CKD and to normal controls.

\section{Methods}

\section{Participants}

Patients were enrolled from local dialysis units, outpatient nephrology clinics and the Thomas E. Starzl Transplant Institute in western Pennsylvania between April 2004 and November 2006. Patients were eligible to participate if they were $>18$ years of age, had an estimated glomerular filtration rate (eGFR) $<30 \mathrm{ml} /$ $\mathrm{min} / 1.73 \mathrm{~m}^{2}$ or were on maintenance dialysis (either HD or PD). In order to have a study sample in the steady state of their health, without any acute medical condition that could affect the results, patients were excluded from participation if they had: craniofacial abnormalities, actively treated sleep apnea, active malignancy, active infection, pulmonary disease using home oxygen therapy, active coronary artery disease within the last 6 months, advanced cirrhosis, advanced dementia, active alcohol abuse, or refractory psychiatric disease ascertained by medical records and confirmed by interview. This study was approved by the University of Pittsburgh institutional review board (protocol numbers: 312047, 501068,604042 ) and all participants provided informed consent.

\section{Control Patients without Kidney Disease}

Control subjects without known CKD were drawn from an archival database of 820 healthy participants studied in $20 \mathrm{Na}$ tional Institutes of Health $(\mathrm{NIH})$-funded studies at the University of Pittsburgh between 1988 and 2006. Although the specific inclusion/exclusion criteria differed somewhat among these studies, all control participants were required to be in good general health, with only minor, well-controlled medical conditions as determined by medical history and physical examination. In addition, they had no current psychiatric illness by structured psychiatric interviews (the Schedule of Affective Disorders and Schizophrenia, SADS or the Structured Clinical Interview for DSM-IV, SCID) [9], and no current sleep disorder by clinical history. The information available on the archived participants consisted of demographic information and 7 days worth of sleep diary data. Controls were matched on age, gender and race to the patients in this study by a series of iterative queries against the archival database attempting to match the age ( \pm 5 years), gender and racial distribution of the reference group to the patient par- ticipants. If a perfectly matched control for all 3 characteristics could not be located in the database, we used age and gender to carry out the matching.

\section{Data Collection and Validation}

Baseline data collection included a brief standardized health interview and a self-completed questionnaire, assessment of current antihypertensive medication use, blood pressure and anthropometric measurements. The self-completed questionnaire collected information on age, gender, race (categorized as AfricanAmerican or European-American), employment and educational status (high school graduates or higher versus less than high school education).

Kidney function in non-dialysis dependent patients was estimated by the Modification of Diet in Renal Disease (MDRD) GFR estimating equation [10]. Diabetes was defined as current use of insulin or oral hypoglycemic agents, while chronic heart failure $(\mathrm{CHF})$ was ascertained by self-report. Presence of restless legs syndrome (RLS) was characterized using the Johns Hopkins RLS Severity Scale (JHRLSS), comprising 9 diagnostic questions to establish the essential criteria for RLS and exclude other common diagnoses. This questionnaire has been shown to have $92 \%$ sensitivity and $95 \%$ specificity when compared to the gold standard of a clinical diagnosis by a sleep disorders specialist [11]. Depression was characterized as present using both the Patient Health Questionnaire [12] (PHQ-9; score of 9 and above) and/or by use of antidepressant medications. The PHQ-9 is a 9-item tool that assesses the patients' frequency of experiencing depressive thoughts or feelings over the prior 2 weeks. In patients on HD, PHQ-9 scores $>9$ are $92 \%$ sensitive and specific for a diagnosis of depressive disorder $[5,13,14]$.

Laboratory data available in a 3-month period prior to the time of study were collected from patient's medical records and averaged. Such data included hemoglobin, serum creatinine and blood urea nitrogen (BUN), serum bicarbonate, potassium, calcium, phosphorous, and serum albumin.

\section{Instruments}

The Pittsburgh Sleep Diary (PghSD) was developed as a pen and paper diary of sleep-wake behavior [15] yielding daily estimates of bedtimes, waketimes, sleep latency, wake after sleep onset, mode of awakening and ratings of sleep quality, mood, and alertness on wakening. The waketime portion of the PghSD assesses sleep quality, mood and alertness by a visual analog scale (VAS) that ranges from $0-100$ with higher scores representing less sleepiness, better mood and increased alertness. Patients were instructed to complete these diaries each morning for up to 14 consecutive days irrespective of their dialysis schedule.

To characterize a profile of HRQOL in standardized domains we used the Short Form-36 (SF-36), which consists of 8 dimensions: (1) physical functioning (PF), (2) role limitations due to physical functioning (RP), (3) bodily pain (BP), (4) general health perceptions (GH), (5) vitality (VT), (6) social functioning (SF), (7) role limitations due to emotional functioning (RE), and (8) mental health $(\mathrm{MH})$. Raw scores are transformed into a score between 0 and 100 for each dimension, with higher scores indicating better performance [16]. The 8 scales of the SF-36 are hypothesized to form 2 distinct higher ordered clusters according to the physical and mental health variance that they have in common [17]. The PF, $\mathrm{RP}$ and BP scales primarily correlate with the physical dimension, 
whereas the, RE and MH mostly contribute to the mental component. The GH, SF and VT have considerable correlations with both physical and mental dimensions of HRQOL [16]. In order to avoid an overlap between the elements of the PHQ- 9 and the components of the SF-36, we used only the primary members of the physical domain and the GH subscale of the SF-36 instrument. As this instrument was completed only once in this study, it cannot be expected to capture the day-to-day variability of symptoms among patients with CKD and ESRD. However, it does provide a static picture of patients' perception of HRQOL at the beginning of the study [18] and potentially account for residual confounding in associations of mood, sleep quality, alertness and their variability.

\section{Statistical Methods}

Descriptive statistics was used to examine the distribution of all independent variables, including demographics and other baseline characteristics. For variables measured on a ratio or interval scale, the mean and the standard deviation were determined as a measure of central tendency and dispersion, respectively. For categorical variables, the frequencies of responses at each level were used.

For the analyses of repeated responses in sleep quality, mood, and alertness, population-averaged methods for longitudinal data, i.e. generalized estimating equations (GEE), were used [19, 20]. These methods allow one to model both the average response (questionnaire score of sleep quality, mood and alertness) as well as their variability while taking into account the possible correlations between repeated assessments in the same individual. In order to apply GEEs one specifies regression (sub-)models for the mean score in the domains of sleep quality, mood and alertness as well as their standard deviation (day-to-day variability) in terms of baseline predictors (patient group, demographics and static HRQOL assessments). The GEE method then reports separate coefficients for the effects of these predictors on the mean and the standard deviation of each domain score; the coefficients in the sub-model for the mean are interpreted as the change in the mean response associated with a unit change in the predictor. On the other hand, the coefficients in the sub-model for the standard deviation are ratios that quantify how many times larger the standard deviation is in the presence or the absence of the predictor. All analyses were performed in $R$ version 2.7 with the $R$ library geepack [21, 22].

\section{Results}

\section{Study Population}

A total of 121 patients with renal disease were approached and agreed to participate in the study. These patients provided both sleep diary data as well as reasons for failing to complete them. Reasons offered for noncompletion included hospital admissions and acute illness, daily activities interfering with completion of diaries, and problems with sleep diary data entry. There were no significant differences in the age and gender of excluded and included participants, except of race (those with complete diaries were significantly more likely to be
European-American). Out of the original study population, 92 patients provided complete sleep diary data and were evaluated. These patients were linked to 91 controls matched by computer for age, sex and race. The final study sample consisted of 183 participants from which 1,869 days of sleep diary data were collected.

Twenty-three patients (25\%) had CKD stages 4 and 5 with an average estimated glomerular filtration rate (eGFR) of $13.6( \pm 4.3) \mathrm{ml} / \mathrm{min} / 1.73 \mathrm{~m}^{2}$ and 59 (75\%) were dialysis dependent (ESRD). Fifty-six individuals with ESRD (61\%) were receiving thrice weekly in-center HD and 13 (14\%) were using PD. For the HD sample, the average single-pool Kt/V was 1.63 ( \pm 0.35$)$, while for the PD patients the average weekly Kt/V was 1.94 ( \pm 0.7$)$. Most of the HD patients were dialyzed during the morning dialysis shift (66\%). None of them was dialyzed in the evening or during the night shifts. Other characteristics of the population with renal dysfunction are shown in table 1. The CKD group had younger, more male and fewer diabetic patients than the ESRD group. The CKD group had also lower serum levels of creatinine and phosphorus, and a lower PF subscale score (table 1). Notably, there were no statistically significant differences in the distribution of mean hemoglobin among the 2 groups of patients with renal disease. Of the 91 controls matched to the patient sample, the average age of controls was 52.4 years ( $\mathrm{p}=0.59$ vs. patients), 63.7\% ( $\mathrm{n}=58, \mathrm{p}=0.96$ vs. patients) were men, and $82.4 \%(\mathrm{n}=75, \mathrm{p}=0.02$ vs. patients) were European-American.

\section{Norms for Mood, Sleep Quality and Alertness}

Overall, participants without known renal disease had high self-rated scores of their mood, sleep quality and alertness (fig. 1, left) and a relatively stable day-to-day variation in the mean (fig. 2, left graph in each row). The mean and the standard deviation of the controls were $79.2 \pm 15.8,76.7 \pm 17.1$ and $77.0 \pm 19.0$ for mood, sleep quality and alertness, respectively. In adjusted models for these norms (table 2) younger age, female gender and European-A merican race were associated with better (higher mean) and less variable mood (ratio of standard deviations $<1$ in table 2 ). There were no significant associations between demographic characteristics and sleep quality or alertness.

\section{Sleep Quality, Mood, and Alertness in Patients Compared to Controls}

The distribution of sleep quality, mood, and alertness scores and the day-to-day variability in these domains for the CKD and ESRD samples relative to controls are shown 
Table 1. Population characteristics and SF-36 data of study patients

\begin{tabular}{|c|c|c|c|c|}
\hline Variable & $\begin{array}{l}\text { All patients } \\
(\mathrm{n}=92)\end{array}$ & $\begin{array}{l}\text { CKD } \\
(n=23)\end{array}$ & $\begin{array}{l}\text { ESRD } \\
(n=69)\end{array}$ & $\begin{array}{l}\text { p value } \\
\text { (test of equality) }\end{array}$ \\
\hline Age, years & $52.8(15.3)$ & $46.1(11.7)$ & $54.7(15.2)$ & 0.01 \\
\hline Male & $57(62.0 \%)$ & $19(83 \%)$ & $38(55 \%)$ & 0.03 \\
\hline White & $61(66.3 \%)$ & $19(83 \%)$ & $42(61 \%)$ & 0.07 \\
\hline BMI & $27.1(5.1)$ & $28.0(4.2)$ & $26.8(5.3)$ & 0.21 \\
\hline High school education & $35(38.0 \%)$ & $6(26.1 \%)$ & $29(42.0 \%)$ & 0.22 \\
\hline Employed & $21(22.8 \%)$ & $8(34.8 \%)$ & $13(18.8 \%)$ & 0.15 \\
\hline Diabetes & $32(34.8 \%)$ & $4(17.4 \%)$ & $28(41 \%)$ & 0.05 \\
\hline $\mathrm{CHF}$ & $14(15.6 \%)$ & $3(13.0 \%)$ & $11(16.4 \%)$ & 0.99 \\
\hline Depression & $17(18.7 \%)$ & $1(4 \%)$ & $16(23 \%)$ & 0.06 \\
\hline RLS & $30(34.9 \%)$ & $8(34.8 \%)$ & $22(34.9 \%)$ & 0.99 \\
\hline Total number of antihypertensives & $2.0 \pm 1.4$ & $2.5 \pm 4.2$ & $1.9 \pm 1.3$ & 0.14 \\
\hline Use of $\beta$-blockers & $49(53.8 \%)$ & $11(47.8 \%)$ & $38(55.9 \%)$ & 0.63 \\
\hline Hemoglobin, g/dl & $11.8 \pm 1.3$ & $11.7 \pm 1.21$ & $11.9 \pm 1.3$ & 0.51 \\
\hline Serum potassium, $\mathrm{mEq} / \mathrm{l}$ & $4.8 \pm 0.8$ & $4.9 \pm 0.5$ & $4.7 \pm 0.9$ & 0.06 \\
\hline Serum bicarbonate, $\mathrm{mEq} / \mathrm{l}$ & $23.4 \pm 3.0$ & $22.8 \pm 3.3$ & $23.6 \pm 2.9$ & 0.15 \\
\hline Serum calcium, g/dl & $9.1 \pm 0.6$ & $9.1 \pm 0.5$ & $9.1 \pm 0.66$ & 0.81 \\
\hline Phosphorus, mg/dl & $5.1 \pm 1.4$ & $4.6 \pm 0.8$ & $5.3 \pm 1.4$ & 0.04 \\
\hline $\mathrm{BUN}, \mathrm{mg} / \mathrm{dl}$ & $56.3 \pm 18.4$ & $57.2 \pm 13.5$ & $56.0 \pm 19.7$ & 0.49 \\
\hline Serum creatinine, $\mathrm{mg} / \mathrm{dl}$ & $7.8 \pm 3.4$ & $5 \pm 1.7$ & $8.7 \pm 3.3$ & $<0.001$ \\
\hline Serum albumin, $\mathrm{g} / \mathrm{dl}$ & $3.9 \pm 0.5$ & $3.9 \pm 0.7$ & $3.87 \pm 0.4$ & 0.49 \\
\hline Physical component scale & $39.9 \pm 6.9$ & $41.2 \pm 8.3$ & $39.5 \pm 6.3$ & 0.18 \\
\hline Mental component scale & $45.4 \pm 7.1$ & $44.8 \pm 7.4$ & $45.6 \pm 7.1$ & 0.85 \\
\hline $\mathrm{PF}$ & $60.9 \pm 26.4$ & $70.2 \pm 27.7$ & $57.8 \pm 25.4$ & 0.05 \\
\hline $\mathrm{RP}$ & $56.1 \pm 43$ & $55.7 \pm 46.9$ & $56.2 \pm 42.0$ & 0.94 \\
\hline $\mathrm{BP}$ & $61.8 \pm 29.8$ & $64.2 \pm 31.1$ & $61 \pm 29.5$ & 0.60 \\
\hline $\mathrm{RE}$ & $33 \pm 44.7$ & $36.4 \pm 45.9$ & $31.8 \pm 44.7$ & 0.77 \\
\hline $\mathrm{MH}$ & $77.2 \pm 16.6$ & $77 \pm 14.1$ & $77.2 \pm 17.5$ & 0.50 \\
\hline SF & $70.2 \pm 24.9$ & $73.3 \pm 26.5$ & $69.1 \pm 24.5$ & 0.43 \\
\hline VT & $47.1 \pm 20.9$ & $45.2 \pm 18.8$ & $47.7 \pm 21.7$ & 0.63 \\
\hline $\mathrm{GH}$ & $44.1 \pm 20.0$ & $38.9 \pm 19.8$ & $45.9 \pm 20.0$ & 0.19 \\
\hline
\end{tabular}

$\mathrm{p}$ value is the result of testing the equality of $\mathrm{CKD}$ to $\mathrm{HD}$ to $\mathrm{PD}(\mathrm{CKD}=\mathrm{HD}=\mathrm{PD})$. Hemoglobin (whole blood) in g/dl may be converted to $\mathrm{g} / \mathrm{l}$ by multiplying by 10.0 ; serum potassium in $\mathrm{mEq} / \mathrm{l}$ to $\mathrm{mmol} / \mathrm{l}$ by multiplying by 1.0 ; serum bicarbonate in $\mathrm{mEq} / \mathrm{l}$ to $\mathrm{mmol} / \mathrm{l}$ by multiplying by 1.0 ; serum calcium in $\mathrm{mg} / \mathrm{dl}$ to $\mathrm{mmol} / \mathrm{l}$ by multiplying by 0.25 ; serum phosphorus in $\mathrm{mg} / \mathrm{dl}$ to $\mathrm{mmol} / \mathrm{l}$ by multiplying by 0.323 ; BUN in $\mathrm{mg} / \mathrm{dl}$ to $\mathrm{mmol} / \mathrm{l}$ by multiplying by 0.357 ; serum creatinine in $\mathrm{mg} / \mathrm{dl}$ to $\mu \mathrm{mol} / \mathrm{l}$ by multiplying by 88.4 ; serum albumin in $\mathrm{g} / \mathrm{dl}$ may be converted to $\mathrm{g} / \mathrm{l}$ by multiplying by 10 .

in figure 1 (middle-right) and (fig. 2, middle-right) respectively. In unadjusted comparisons (table 3), patients with CKD stages 4-5 demonstrated statistically significant reductions in their average scores in sleep quality and alertness relative to controls, while patients on dialysis had lower performance in all 3 domains. Sleep quality was affected the most with reductions of 13.4 and 20.8 from the normative response in the CKD and ESRD groups, respectively. Day-to-day variability of mood, sleep quality and alertness was also higher in the ESRD group (table 3); the standard deviation of scores was 71,72 and $52 \%$ greater than controls. Even though there was a trend for mood, sleep quality and alertness scores to be more variable in the CKD group relative to controls, statistical significance was attained only for the sleep domain. These differences in average sleep quality, mood, and alertness scores and their variability were significant and of same magnitude for all 3 domains after adjusting for age, gender, and race (not shown).

\section{Predictors of Sleep Quality, Mood and Alertness and} Their Variability among Patients with Kidney Disease

In analyses adjusting for demographic factors, body mass index (BMI), high school education, employment 
Fig. 1. Mean and standard deviation of mood, sleep quality, and alertness in patients and controls. = Average score. Error bar represents standard deviation of the score in each domain (mood, sleep quality and alertness). Number of observations: 651 (controls), 308 (stage 4-5 CKD) and 880 (ESRD).

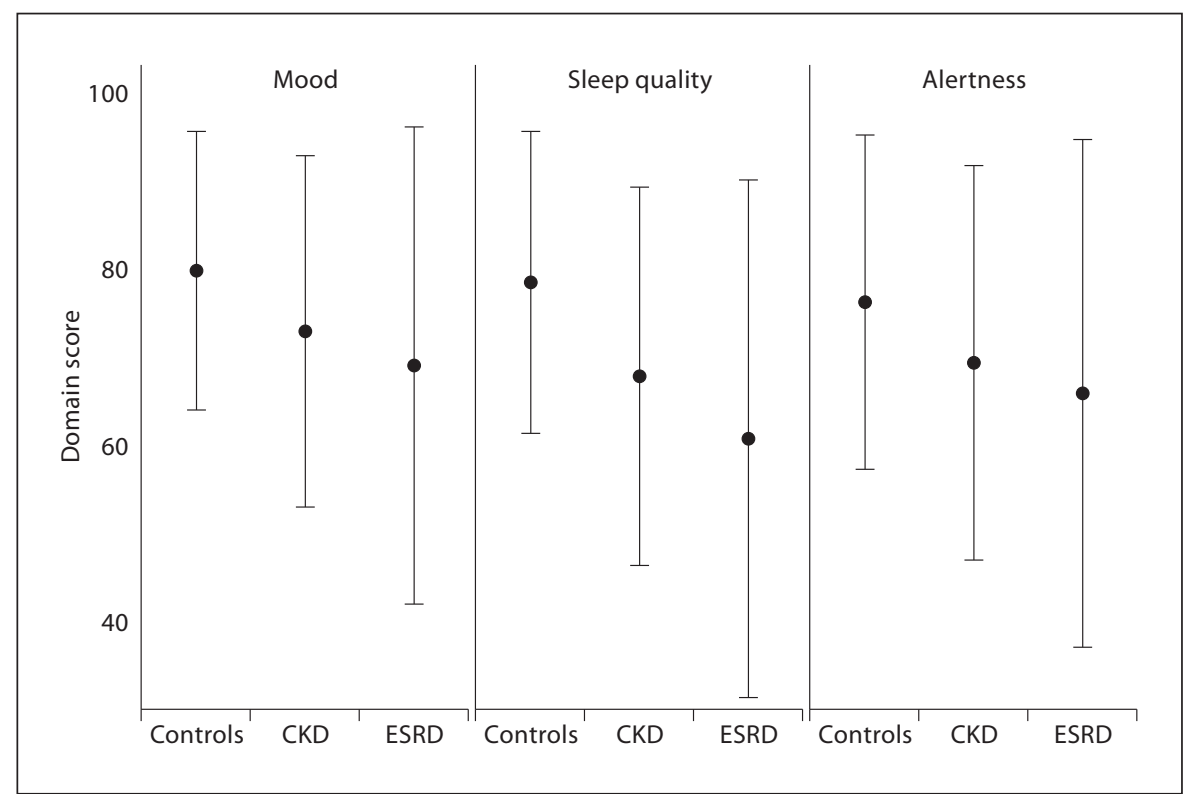

status, CHF, depression, RLS, total number of antihypertensives taken, usage of beta-blockers ( $\beta$-blockers) and SF-36 components, dialysis dependency was associated with lower average scores in mood, sleep quality and alertness (table 4). A better (higher) GH score was associated with better scores in mood and sleep quality, while less (higher) BP score predicted better performance on mood/sleep. Patients with a higher PF score scored worse in all 3 domains. Older age was associated with better average mood and alertness, while African-Americans had also higher scores in mood and alertness than EuropeanAmericans. BMI was also associated with worse sleep quality. There was no statistically significant association between high school education, employment status, CHF, presence of RLS, total number of antihypertensives used, usage of $\beta$-blockers, depression and female gender with any of the 3 domains.

Statistically significant predictors of variability included dialysis dependency for mood and alertness (increase in variability of mood and alertness by about $35 \%$, $\mathrm{p}<0.001$ ), while better (higher scores) general health led to less variable mood scores by $26 \%(p=0.009)$. In addition, there was a significant effect of employment status on the variability of the mood and alertness scores. Employed patients showed 39\% more variable mood ( $\mathrm{p}<$ $0.001)$ and $24 \%$ more variable alertness $(\mathrm{p}=0.05)$. Notably there was no effect of the shift of dialysis (morning vs. afternoon) on the variability of scores for any of the 3 domains in the subgroup of patients receiving HD. Patients dialyzed in morning shifts had 14 and 19\% greater variability in their mood and alertness scores $(\mathrm{p}=0.45$ and 0.19 , respectively) and $12 \%$ less variable sleep quality ( $\mathrm{p}=$ 0.35 ) compared to patients dialyzed during the afternoon.

\section{Sensitivity Analysis}

The analyses shown in tables 2-4 were repeated with alternative techniques for repeated measures data (linear normal mixed models) and there was no substantial difference in the parameter estimates. To guard against residual confounding by the differences in the laboratory values, we constructed GEE models that included the association between diabetic status, laboratory values and sleep quality, mood and alertness. In these extended models, there was no substantial difference in the coefficients of the predictors in tables 2-4. Furthermore phosphorus level, hemoglobin, bicarbonate and diabetes were not statistically significant predictors of the average sleep quality, mood and alertness scores and their variability.

\section{Discussion}

In this report of 92 patients with advanced renal disease and 91 matched healthy controls with 1,869 days of sleep diary data, we demonstrate a marked impairment and a higher day-to-day variability in sleep quality, mood and alertness relative to norms for these domains as- 
Fig. 2. Day-to-day variability in mood, sleep quality, and alertness in patients and controls. Mean and standard deviation of each of the 3 domain scores by day of the study are presented. $=$ Mean score in each day. Error bar represents standard deviation of the score computed over all patients completing the diary each day.

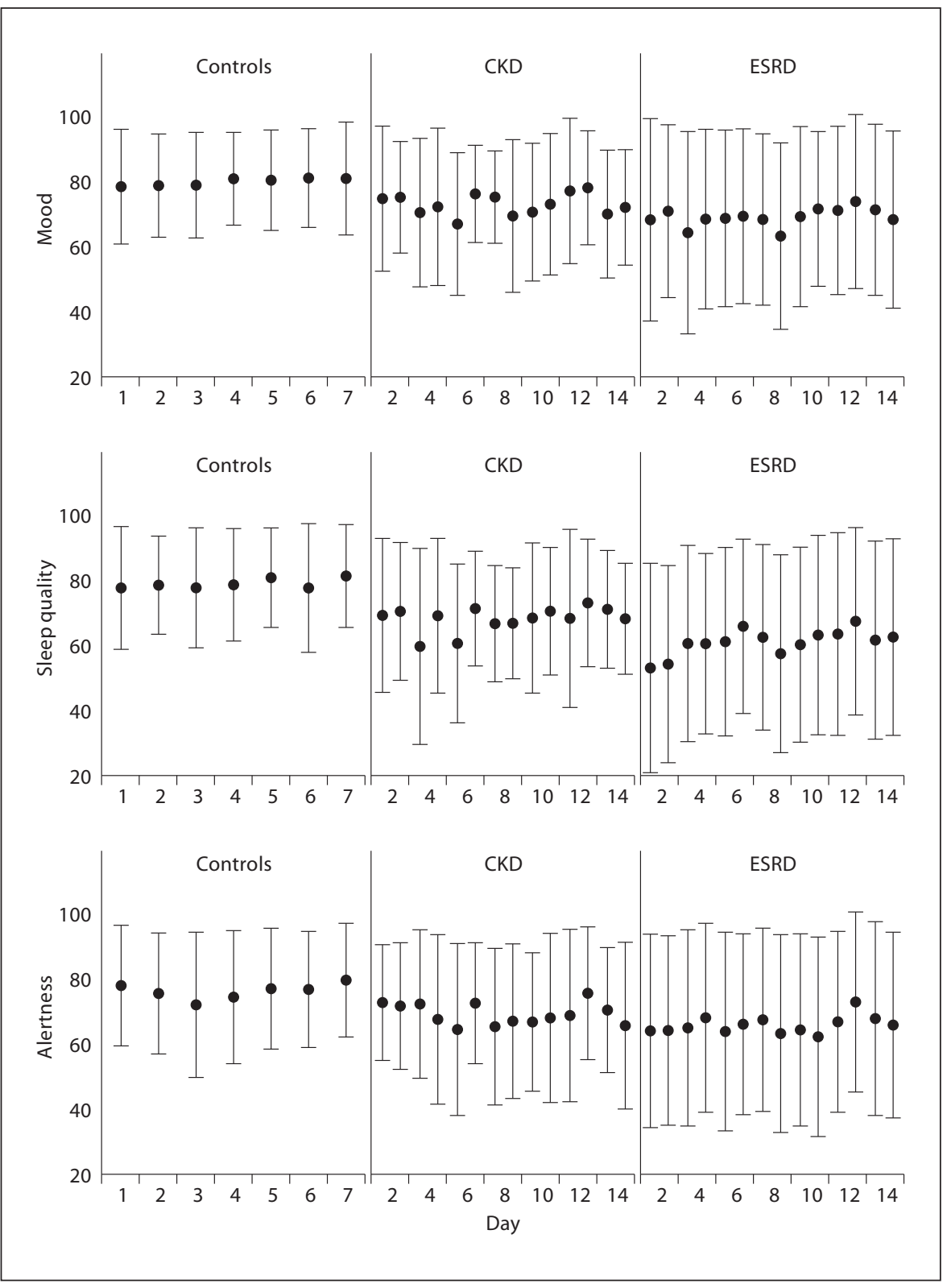

sessed in the controls. Dependence on dialysis appears to further exacerbate the average severity of these symptoms compared to CKD stages 4-5, and may also be associated with increased variability in some of these domains. In contrast to normal controls, African-American patients experienced better mood, sleep quality and daytime performance (alertness). These findings are novel in quantifying the average performance in 3 important quality of life domains as well as its variability against normative standards with important implications for clinical research and practice.
Our findings extend previous work that showed a high rate of sleep complaints in patients with renal dysfunction by using diary methods and by assessing daily variability in sleep domains. Patients with ESRD have a remarkably high rate of sleep complaints and a higher prevalence of sleep disorders than the general population [4, 23]. Studies of patients on maintenance HD have found that $50-80 \%$ report some sleep complaint (delayed sleep onset, frequent awakening, restlessness) or excessive daytime somnolence suggestive of poor sleep quality [24-27]. The poor sleep quality of these patients may be due to the 
Table 2. Predictors of mean and standard deviation for mood, sleep quality, and alertness normative scores

\begin{tabular}{llll}
\hline & Mood & Quality of sleep & Alertness \\
\hline $\begin{array}{lll}\text { Mean }^{1,2} \\
\text { Age (per year) }\end{array}$ & $1.7(0.4,3.0)$ & & \\
& $\mathrm{p}=0.009$ & $0.8(-0.5,2.2)$ & $1.5(-0.1,3.0)$ \\
Female (vs. male) & $7.0(2.0,12.0)$ & $\mathrm{p}=0.2$ & $\mathrm{p}=0.06$ \\
& $\mathrm{p}=0.006$ & $3.1(-1.3,7.6)$ & $2.8(-4.4,10.0)$ \\
African-American race & $-7.7(-14.2,-1.2)$ & $\mathrm{p}=0.2$ & $-2.4(-11.0,6.3)$ \\
& $\mathrm{p}<0.001$ & $-2.0(-8.0,3.9)$ & $\mathrm{p}=0.6$ \\
\hline Standard deviation ${ }^{3}$ & & $\mathrm{p}=0.5$ & \\
Age & $0.93(0.87,0.99)$ & $0.99(0.93,1.05)$ & $0.95(0.89,1.01)$ \\
Female & $\mathrm{p}=0.02$ & $\mathrm{p}=0.2$ & $\mathrm{p}=0.09$ \\
& $0.71(0.56,0.90)$ & $0.85(0.69,1.05)$ & $\mathrm{p}=0.86$ \\
African-American race & $\mathrm{p}=0.005$ & $\mathrm{p}=0.2$ & $0.96(0.6), 1.6)$ \\
& $1.35(-14.19,-1.17)$ & $1.07(0.82,1.40)$ & $\mathrm{p}=0.85$ \\
\hline
\end{tabular}

${ }^{1}$ The first number in each cell is the coefficient quantifying the change in the average mood, sleep quality and alertness in the presence of the predictor (or per 1 unit change for continuous predictors such as age). Number in parentheses is the $95 \%$ confidence interval (uncertainty of the model for the value of the coefficient), and the final number is the p value measuring statistical significance.

${ }^{2}$ Models for average performance adjusted for a linear trend in day-to-day performance in each of the 3 domains.

${ }^{3}$ The first number in each cell is the coefficient of the model giving the ratio of the standard deviation of mood, sleep quality and alertness in the presence of the predictor (or per 1 unit change for continuous predictors such as age). Number in parentheses is the $95 \%$ confidence interval (uncertainty of the model for the value of the coefficient), and the final number is the $\mathrm{p}$ value measuring statistical significance.

Table 3. Unadjusted analyses of mean and standard deviation of mood, sleep quality and alertness domain scores in patients with CKD, and ESRD compared to normal controls

\begin{tabular}{llll}
\hline & Mood & Quality of sleep & Alertness \\
\hline Mean 1 & & & \\
CKD (vs. controls) & $-7.02(-14.2,0.2)$ & $-13.39(-19.4,-7.4)$ & $-8.58(-16.0,-1.1)$ \\
& $\mathrm{p}=0.06$ & $\mathrm{p}<0.001$ & $\mathrm{p}=0.02$ \\
ESRD (vs. controls) & $-12.1(-17.9,-6.31)$ & $-20.8(-26.4,-15.2)$ & $-13.5(-19.7,-7.3)$ \\
& $\mathrm{p}<0.001$ & $\mathrm{p}<0.001$ & $\mathrm{p}<0.001$ \\
\hline Standard Deviation ${ }^{2}$ & $1.26(0.97,1.63)$ & & \\
CKD (vs. controls) & $\mathrm{p}=0.08$ & $1.26(1.06,1.49)$ & $1.18(0.95,1.47)$ \\
& $1.71(1.46,2.02)$ & $\mathrm{p}=0.007$ & $\mathrm{p}=0.1$ \\
ESRD (vs. controls) & $\mathrm{p}<0.001$ & $1.72(1.50,2.0)$ & $1.52(1.27,1.80)$ \\
& $\mathrm{p}<0.001$ & $\mathrm{p}<0.001$ \\
\hline
\end{tabular}

${ }^{1}$ The first number in each cell is the coefficient quantifying the change in the average mood, sleep quality and alertness in the presence of the predictor (or per 1 unit change for continuous predictors such as age). Number in parentheses is the $95 \%$ confidence interval (uncertainty of the model for the value of the coefficient), and the final number is the $\mathrm{p}$ value measuring statistical significance.

${ }^{2}$ The first number in each cell is the coefficient of the model giving the ratio of the standard deviation of mood, sleep quality and alertness in the presence of the predictor (or per 1 unit change for continuous predictors such as age). Number in parentheses is the $95 \%$ confidence interval (uncertainty of the model for the value of the coefficient), and the final number is the $\mathrm{p}$ value measuring statistical significance. 
Table 4. Predictors of mean mood, sleep quality and alertness domain scores in patients on renal replacement therapy (HD or PD) and patients with CKD

\begin{tabular}{|c|c|c|c|}
\hline & Mood & Quality of sleep & Alertness \\
\hline ESRD (relative to CKD) & $\begin{array}{l}-11.3(-19.9,-2.7) \\
p=0.01\end{array}$ & $\begin{array}{l}-10.5(-18.5,-2.5) \\
p=0.01\end{array}$ & $\begin{array}{l}-12.7(-22.1,3.3) \\
p=0.008\end{array}$ \\
\hline Age & $\begin{array}{l}3.0(0.5,5.5) \\
\mathrm{p}=0.02\end{array}$ & $\begin{array}{l}0.08(-2.1,2.3) \\
p=0.94\end{array}$ & $\begin{array}{l}3.1(0.2,5.9) \\
p=0.035\end{array}$ \\
\hline Female & $\begin{array}{l}3.7(-2.9,10.4) \\
p=0.27\end{array}$ & $\begin{array}{l}6.0(-1.2,13.3) \\
p=0.1\end{array}$ & $\begin{array}{l}4.1(-3.2,11.3) \\
p=0.27\end{array}$ \\
\hline African-American race & $\begin{array}{l}9.8(2.0,17.5) \\
p=0.01\end{array}$ & $\begin{array}{l}6.2(-1.6,14.0) \\
p=0.12\end{array}$ & $\begin{array}{l}12.3(3.7,21.0) \\
\mathrm{p}=0.005\end{array}$ \\
\hline BMI & $\begin{array}{l}-0.8(-1.6,0.02) \\
\mathrm{p}=0.06\end{array}$ & $\begin{array}{l}-0.9(-1.5,-0.2) \\
\mathrm{p}=0.01\end{array}$ & $\begin{array}{l}-0.7(-1.5,0.1) \\
\mathrm{p}=0.1\end{array}$ \\
\hline High school education & $\begin{array}{l}1.5(-6.7,9.6) \\
p=0.72\end{array}$ & $\begin{array}{l}-0.9(-7.7,5.9) \\
p=0.8\end{array}$ & $\begin{array}{l}4.1(-5.3,13.6) \\
p=0.39\end{array}$ \\
\hline Employed & $\begin{array}{l}0.1(-8.7,8.9) \\
\mathrm{p}=0.98\end{array}$ & $\begin{array}{l}3.3(-5.4,12.1) \\
p=0.46\end{array}$ & $\begin{array}{l}2.1(-7.4,11.6) \\
p=0.67\end{array}$ \\
\hline $\mathrm{CHF}$ & $\begin{array}{l}-2.9(-15.2,9.3) \\
\mathrm{p}=0.64\end{array}$ & $\begin{array}{l}-6.1(-18.0,5.8) \\
p=0.31\end{array}$ & $\begin{array}{l}-7.7(-21.8,6.4) \\
p=0.28\end{array}$ \\
\hline Depression & $\begin{array}{l}2.8(-7.5,13.2) \\
p=0.59\end{array}$ & $\begin{array}{l}1.9(-7.2,10.9) \\
p=0.69\end{array}$ & $\begin{array}{l}2.9(-9.6,15.3) \\
p=0.65\end{array}$ \\
\hline Presence of RLS & $\begin{array}{l}2.98(-5.8,11.8) \\
p=0.51\end{array}$ & $\begin{array}{l}-0.7(-9.7,8.4) \\
p=0.88\end{array}$ & $\begin{array}{l}-2.8(-11.5,6.0) \\
p=0.006\end{array}$ \\
\hline Total number antihypertensives & $\begin{array}{l}2.0(-0.7,4.8) \\
\mathrm{p}=0.15\end{array}$ & $\begin{array}{l}1.45(-1.4,4.3) \\
p=0.32\end{array}$ & $\begin{array}{l}1.4(-2.1,4.8) \\
\mathrm{p}=0.44\end{array}$ \\
\hline Use of $\beta$-blockers & $\begin{array}{l}-4.3(-12.6,4.0) \\
p=0.31\end{array}$ & $\begin{array}{l}-1.7(-10.3,6.8) \\
p=0.69\end{array}$ & $\begin{array}{l}-4.3(-13.7,5.2) \\
p=0.37\end{array}$ \\
\hline $\mathrm{BP}$ & $\begin{array}{l}13.5(4.2,22.8) \\
p=0.005\end{array}$ & $\begin{array}{l}13.2(3.4,23.0) \\
p=0.008\end{array}$ & $\begin{array}{l}10.9(-0.5,22.4) \\
p=0.06\end{array}$ \\
\hline $\mathrm{RP}$ & $\begin{array}{l}-3.6(-11.6,4.4) \\
p=0.37\end{array}$ & $\begin{array}{l}1.8(-5.5,9.1) \\
p=0.63\end{array}$ & $\begin{array}{l}-3.9(-11.9,4.1) \\
p=0.33\end{array}$ \\
\hline $\mathrm{GH}$ & $\begin{array}{l}10.9(2.4,19.3) \\
p=0.01\end{array}$ & $\begin{array}{l}12.9(5.4,20.5) \\
\mathrm{p}<0.001\end{array}$ & $\begin{array}{l}6.6(-3.2,16.4) \\
p=0.18\end{array}$ \\
\hline $\mathrm{PF}$ & $\begin{array}{l}-18.7(-32.0,-5.5) \\
\mathrm{p}=0.006\end{array}$ & $\begin{array}{l}-14.9(-25.5,-4.4) \\
\mathrm{p}=0.006\end{array}$ & $\begin{array}{l}-19.6(-33.4,-5.7) \\
\mathrm{p}=0.006\end{array}$ \\
\hline
\end{tabular}

The first number in each cell is the coefficient quantifying the change in the average mood, sleep quality and alertness in the presence of the predictor (or per 1 unit change for continuous predictors such as age). Number in parentheses is the $95 \%$ confidence interval (uncertainty of the model for the value of the coefficient), and the final number is the $\mathrm{p}$ value measuring statistical significance. All models are adjusted for a linear trend in day-to-day performance in each of the 3 domains.

adjustment of their sleep-wake behavior to the time requirements of the dialysis regimen, and this adjustment is likely different for patients on home therapies versus in-center HD. In PD, the need to adhere to a long therapy, delivered at a relatively inflexible schedule may result in an individual spending more time in bed than he or she would have done otherwise. If patient oversleeps as a result of the extra sleep time one day, then he or she may experience a sleepless night the next day leading to fluctuating sleep quality and changes in day time perfor- mance (alertness) and possibly mood. On the other hand, a patient receiving in-center HD would have to adjust (shorten) one's wake-up time in order to show up for his dialysis treatment the same day [28]. We postulate that irrespective of the specific nature of this adjustment, the end result is a disruption of the normal sleep behavioral patterns as well as poor and more variable sleep scores of the dialysis population.

A novel finding of our investigations concerns the high variability in mood, sleep quality and alertness reported 
by patients with CKD which was particularly prominent in the ESRD group. Diaries are particularly helpful for the assessment of variability since they provide reliable [29], prospective assessment of symptoms and their day-to-day variation [30] in the participants' usual environment, with limited burden while avoiding recall bias [31, 32]. Hence this higher variability observed in this cohort, is likely a generalizable finding of our study. Since patients with CKD had more variable scores than controls, one possible explanation is that the uremic milieu is at least partly responsible. One could further hypothesize that the additional variability of ESRD relative to CKD patients is related to their dialysis dependency or the timing of dialysis, which could induce alterations in arousal and/ or thermoregulatory processes [33-36]. On the other hand, the greater variability could be interpreted as an attempt by the patients with poor average sleep to 'catch up' when the opportunity presents itself.

Irrespective of the cause of this high variability in symptoms, its presence has important implications for both clinical practice and research. Poor sleep quality in particular has been associated with higher mortality, higher disability and utilization costs in the CKD/ESRD population [40], hence, recognizing its presence may be of particular relevance to the clinical management of these patients. The excess daily variation of symptoms relative to controls implies that a single cross-sectional assessment of patients with renal dysfunction may not be sufficient to correctly classify patients in clinical practice. Previous research has highlighted that renal providers are largely unaware of the presence and severity of symptoms related to sleep quality, daytime performance and mood among patients who are on maintenance HD [6]. One could hypothesize that a high variability in the severity of these symptoms could lead to underdiagnosis if the 'peak' (the 'good' but atypical days) of patients coincides with the day they are assessed [6]. The implications for research programs that directly address these symptoms can be extrapolated from studies in subjects without renal dysfunction to the CKD/ESRD populations [41]. Unless one explicitly acknowledges the potential for the variability to be higher in these patient groups by incorporating repeated assessments, higher sample sizes, and suitable methods [42], the loss of power may be substantial.

It is interesting to note that there was no statistically significant effect of the timing of dialysis (dialysis shift) in our patient population considering that our patients have considerable flexibility in selecting their preferred shift. Previous studies on the impact of dialysis shift on sleep abnormalities, morbidity and mortality are still scarce and heterogeneous in the findings. Two studies by Sabbatini et al. [37] and by Merlino et al. [38] identified dialysis shift as an independent predictor of insomnia and sleep disturbances. On the other hand, in the HEMO study [33] as well as in a more recent evaluation by Bastos et al. [39], there was no statistically significant association between morning dialysis shift and sleep quality, VT or daytime sleepiness. Differences in the patient populations, unit practices (flexibility in allowing patients to select the shift they prefer to dialyze) and possibly the prevalence of depression may account for these discrepant findings. Notwithstanding the lack of association between the time of dialysis shift and poor mood, sleep quality and alertness, we cannot rule out the possibility that a study with a larger sample could find a significant effect.

In this report, African-Americans had higher scores in all 3 domains than European-Americans $(p<0.001)$. This racial association has been noted previously; in a recent cross-sectional study assessing sleep quality by the KDQOL instrument, non African-Americans had a worse sleep quality by about 10 points [43], an effect that is near identical to the one estimated in this report. In the HEMO study population, African-Americans were also noted to have higher unadjusted sleep KDQOL scores [44], while elderly African-American patients had a smaller burden of sleep-related symptoms in a community cohort [45]. Race did not have a protective effect on the healthy control group employed in this study, mirroring findings previously reported in the Cardiovascular Health Study and the Sleep Heart Health Study [46, 47].

The findings of this report should be interpreted in light of the following limitations. First, this is a study of subjective sleep characteristics and their variability, rather than a study of sleep disorders. Therefore, we cannot comment on the nature of sleep disturbances observed. Second, the waking assessments did not account for potential circadian variation in sleep quality, mood and alertness. Consequently, changes that may occur throughout the day will be missed by a single daily measurement of day time performance. Future studies should consider employing frequent assessments across the day to measure diurnal variations. Finally, while our study examined the prevalence of comorbid medical conditions and laboratory abnormalities linked to renal dysfunction, we did not have comparable data in the control group. In addition, by using control subjects derived from an archival database we could not control for the exclusion of individuals with sleep disorders. Studies that employ concurrent, prospectively assessed cases and controls should be undertaken to address this limitation. 
Our findings suggest that future efforts to understand and estimate the importance of sleep disturbances in patients with CKD should not focus exclusively on those with ESRD. The PghSD may serve as a clinical tool to understand the sleep problems of patients with varying stages of CKD. Our assessment of the patient's variability in sleep, mood and daytime performance (alertness) will need to be verified in additional settings and with larger sample sizes. Finally, further work should examine potential biological mediators of impaired sleep, mood, and alertness among patients with advanced chronic kidney disease.

\section{Acknowledgements}

We want to thank Drs. Timothy Monk, Daniel J. Kupfer, Douglass Moul, Charles Reynolds, Martica Hall, and Eric Nofzinger for use of their archived healthy controls. We thank the patients, staff, and physicians who participated in this study.

This work was supported by the Fresenius National Kidney Foundation Young Investigator Grant, Paul Teschan Research Grant, NIH DK66006 and DK77785 (M.L.U.) and NIH MH24652 (D.J.B.). This publication was supported by funds received from the NIH/NCRR/CTSA Grant UL1 RR024153.

\section{References}

$\checkmark 1$ Unruh ML, Weisbord SD, Kimmel PL: Health-related quality of life in nephrology research and clinical practice. Semin Dial 2005; 18:82-90.

2 Jhamb M, Weisbord SD, Steel JL, Unruh M: Fatigue in patients receiving maintenance dialysis: a review of definitions, measures, and contributing factors. Am J Kidney Dis 2008;52:353-365.

- 3 Ramkumar N, Beddhu S, Eggers P, Pappas LM, Cheung AK: Patient preferences for incenter intense hemodialysis. Hemodial Int 2005;9:281-295.

4 Unruh ML, Hartunian MG, Chapman MM, Jaber BL: Sleep quality and clinical correlates in patients on maintenance dialysis. Clin Nephrol 2003;59:280-288.

5 Son YJ, Choi KS, Park YR, Bae JS, Lee JB: Depression, symptoms and the quality of life in patients on hemodialysis for end-stage renal disease. Am J Nephrol 2009;29:36-42.

-6 Weisbord SD, Fried LF, Mor MK, Resnick AL, Unruh ML, Palevsky PM, Levenson DJ, Cooksey SH, Fine MJ, Kimmel PL, Arnold RM: Renal provider recognition of symptoms in patients on maintenance hemodialysis. Clin J Am Soc Nephrol 2007;2:960-967.

7 Abdel-Kader K, Unruh ML, Weisbord SD: Symptom burden, depression, and quality of life in chronic and end-stage kidney disease. Clin J Am Soc Nephrol 2009;4:1057-1064.

-8 Murtagh FE, Addington-Hall JM, Edmonds PM, Donohoe P, Carey I, Jenkins K, Higginson IJ: Symptoms in advanced renal disease: a cross-sectional survey of symptom prevalence in stage 5 chronic kidney disease managed without dialysis. J Palliat Med 2007;10: 1266-1276.

-9 Segal DL, Hersen M, Van Hasselt VB: Reliability of the structured clinical interview for DSM-III-R: an evaluative review. Compr Psychiatry 1994;35:316-327.
10 Levey AS, Bosch JP, Lewis JB, Greene T, Rogers N, Roth D: A more accurate method to estimate glomerular filtration rate from serum creatinine: a new prediction equation. Modification of Diet in Renal Disease Study Group. Ann Intern Med 1999;130:461-470.

11 Allen RP, Earley CJ: Validation of the Johns Hopkins restless legs severity scale. Sleep Med 2001;2:239-242.

12 Lowe B, Unutzer J, Callahan CM, Perkins AJ, Kroenke K: Monitoring depression treatment outcomes with the patient health questionnaire-9. Med Care 2004;42:1194-1201.

13 Odden MC, Whooley MA, Shlipak MG: Depression, stress, and quality of life in persons with chronic kidney disease: the Heart and Soul Study. Nephron 2006;103:c1-c7.

14 Goodwin RD, Kroenke K, Hoven CW, Spitzer RL: Major depression, physical illness, and suicidal ideation in primary care. Psychosom Med 2003;65:501-505.

15 Monk TH, Reynolds CF, Kupfer DJ, Buysse DJ, Coble PA, Hayes AJ, MacHen MA, Petrie SR, Ritenour AM: The Pittsburgh Sleep Diary. J Sleep Res 1994;3:111-120.

$\checkmark 16$ Liem YS, Bosch JL, Arends LR, HeijenbrokKal MH, Hunink MG: Quality of life assessed with the Medical Outcomes Study Short Form 36-Item Health Survey of patients on renal replacement therapy: a systematic review and meta-analysis. Value Health 2007;10:390-397.

17 Ware JE, Jr.: SF-36 health survey update. Spine 2000;25:3130-3139.

18 Kalender B, Ozdemir AC, Dervisoglu E, Ozdemir O: Quality of life in chronic kidney disease: effects of treatment modality, depression, malnutrition and inflammation. Int J Clin Pract 2007;61:569-576.

19 Hanley JA, Negassa A, Edwardes MD, Forrester JE: Statistical analysis of correlated data using generalized estimating equations: an orientation. Am J Epidemiol 2003;157: $364-375$.
$20 \mathrm{Hu}$ FB, Goldberg J, Hedeker D, Flay BR, Pentz MA: Comparison of population-averaged and subject-specific approaches for analyzing repeated binary outcomes. Am J Epidemiol 1998;147:694-703.

21 Højsgaard S, Halekoh U, Yan J: The r package geepack for generalized estimating equation. J Stat Softw 2005;15:1-11.

22 Pinheiro JC, Bates DM: Fitting extended linear models with gls; in Pinheiro JC, Bates DM (eds): Mixed Effects Models in S and SPLUS. New York, Springer, 2000, pp 249266.

23 Unruh ML, Buysse DJ, Dew MA, Evans IV, Wu AW, Fink NE, Powe NR, Meyer KB: Sleep quality and its correlates in the first year of dialysis. Clin J Am Soc Nephrol 2006; 1:802810.

24 Iliescu EA, Yeates KE, Holland DC: Quality of sleep in patients with chronic kidney disease. Nephrol Dial Transplant 2004;19:9599.

25 Holley JL, Nespor S, Rault R: A comparison of reported sleep disorders in patients on chronic hemodialysis and continuous peritoneal dialysis. Am J Kidney Dis 1992;19: 156-161.

26 Unruh ML, Sanders MH, Redline S, Piraino BM, Umans JG, Chami H, Budhiraja R, Punjabi NM, Buysse D, Newman AB: Subjective and objective sleep quality in patients on conventional thrice-weekly hemodialysis: comparison with matched controls from the sleep heart health study. Am J Kidney Dis 2008;52:305-313.

27 Walker S, Fine A, Kryger MH: Sleep complaints are common in a dialysis unit. Am J Kidney Dis 1995;26:751-756.

28 Barmar B, Dang Q, Isquith D, Buysse D, Unruh M: Comparison of sleep/wake behavior in CKD stages 4 to 5 and hemodialysis populations using wrist actigraphy. Am J Kidney Dis 2009;53:665-672. 
29 Csikszentmihalyi M, Larson R: Validity and reliability of the experience-sampling method. J Nerv Ment Dis 1987;175:526-536.

- 30 Levitt H, Wood A, Moul DE, Hall M, Germain A, Kupfer DJ, Buysse DJ: A pilot study of subjective daytime alertness and mood in primary insomnia participants using ecological momentary assessment. Behav Sleep Med 2004;2:113-131.

- 31 Gendreau M, Hufford MR, Stone AA: Measuring clinical pain in chronic widespread pain: selected methodological issues. Best Pract Res Clin Rheumatol 2003;17:575-592.

- 32 Moskowitz DS, Young SN: Ecological momentary assessment: what it is and why it is a method of the future in clinical psychopharmacology. J Psychiatry Neurosci 2006; 31:13-20.

-33 Ng YH, Meyer KB, Kusek JW, Yan G, Rocco MV, Kimmel PL, Benz RL, Beddhu S, Dwyer JT, Toto RD, Eknoyan G, Unruh ML: Hemodialysis timing, survival, and cardiovascular outcomes in the hemodialysis (HEMO) study. Am J Kidney Dis 2006:47:614-624.

-34 Bliwise DL, Kutner NG, Zhang R, Parker KP: Survival by time of day of hemodialysis in an elderly cohort. JAMA 2001;286:2690-2694.

- 35 Abbott KC, Reynolds JC, Trespalacios FC, Cruess D, Agodoa LY: Survival by time of day of hemodialysis: analysis of United States Renal Data System Dialysis Morbidity and Mortality Waves III/IV. Am J Kidney Dis 2003;41:796-806.
36 Parker KP, Bliwise DL, Rye DB, De A: Intradialytic subjective sleepiness and oral body temperature. Sleep 2000;23:887-891.

37 Sabbatini M, Minale B, Crispo A, Pisani A, Ragosta A, Esposito R, Cesaro A, Cianciaruso B, Andreucci VE: Insomnia in maintenance haemodialysis patients. Nephrol Dial Transplant 2002;17:852-856.

-38 Merlino G, Piani A, Dolso P, Adorati M, Cancelli I, Valente M, Gigli GL: Sleep disorders in patients with end-stage renal disease undergoing dialysis therapy. Nephrol Dial Transplant 2006;21:184-190.

39 Bastos JP, Sousa RB, Nepomuceno LA, Gutierrez-Adrianzen OA, Bruin PF, Araujo ML, Bruin VM: Sleep disturbances in patients on maintenance hemodialysis: role of dialysis shift. Rev Assoc Med Bras 2007;53:492-496.

40 Hays RD, Kallich JD, Mapes DL, Coons SJ, Carter WB: Development of the kidney disease quality of life (KDQOL) instrument. Qual Life Res 1994;3:329-338.

41 Wohlgemuth WK, Edinger JD, Fins AI, Sullivan RJ, Jr: How many nights are enough? The short-term stability of sleep parameters in elderly insomniacs and normal sleepers. Psychophysiology 1999;36:233-244.
42 Ruxton GD: The unequal variance t-test is an underused alternative to student's t-test and the Mann-Whitney U test. Behav Ecol 2006; 17:688-690.

43 Kurella M, Luan J, Lash JP, Chertow GM: Self-assessed sleep quality in chronic kidney disease. Int Urol Nephrol 2005;37:159-165.

-44 Unruh M, Miskulin D, Yan G, Hays RD, Benz R, Kusek JW, Meyer KB: Racial differences in health-related quality of life among hemodialysis patients. Kidney Int 2004;65: 1482-1491.

45 Kutner NG, Bliwise DL, Zhang R: Linking race and well-being within a biopsychosocial framework: variation in subjective sleep quality in two racially diverse older adult samples. J Health Soc Behav 2004;45:99113.

46 Whitney CW, Enright PL, Newman AB, Bonekat W, Foley D, Quan SF: Correlates of daytime sleepiness in 4,578 elderly persons: the Cardiovascular Health Study. Sleep 1998; 21:27-36.

$\checkmark 47$ O'Connor GT, Lind BK, Lee ET, Nieto FJ, Redline S, Samet JM, Boland LL, Walsleben JA, Foster GL: Variation in symptoms of sleep-disordered breathing with race and ethnicity: the Sleep Heart Health Study. Sleep 2003;26:74-79. 